\title{
Vessel Wall Contrast Enhancement: A Diagnostic Sign of Cerebral Vasculitis
}

\author{
Wilhelm Küker ${ }^{a, b}$ Susanne Gaertner ${ }^{c}$ Thomas Nägele ${ }^{d}$ Christian Dopfer ${ }^{\mathrm{e}}$ \\ Martin Schöning ${ }^{\text {e Jens Fiehler }}{ }^{a}$ Peter M. Rothwell ${ }^{b}$ Ulrich Herrlinger ${ }^{f}$ \\ Departments of a Neuroradiology and ${ }^{b}$ Clinical Neurology, University of Oxford, John Radcliffe Hospital, Oxford, UK; \\ Departments of ${ }^{\mathrm{c}}$ Neurology, ${ }^{\mathrm{d}}$ Neuroradiology and ${ }^{\mathrm{e}}$ Neuropaediatrics, University Hospital, Tübingen, and \\ ${ }^{f}$ Department of Neurology, University of Bonn, Bonn, Germany
}

\section{Key Words}

Cerebral vasculitis - Vessel wall contrast enhancement •

Stenosis

\begin{abstract}
Purpose: Inflammatory stenoses of cerebral arteries cause stroke in patients with florid vasculitis. However, diagnosis is often difficult even with digital subtraction angiography (DSA) and biopsy. The purpose of this study was to establish the value of contrast-enhanced MRI, proven to be sensitive to extradural arteritis, for the identification of intracranial vessel wall inflammation. Patients and Methods: Twentyseven patients with a diagnosis of cerebral vasculitis affecting large brain vessels were retrieved from the files: 8 children (2-10 years, 7 female, 1 male) and 19 adults (16-76 years, 10 female, 9 male). Diagnosis was based on histological or serological proof of vasculitis or on clinical and imaging criteria. All MRI examinations included diffusion-weighted imaging, time-of-flight magnetic resonance angiography (TOF-MRA) and contrast-enhanced scans. MRI scans were assessed for the presence of ischemic brain lesions, arterial stenoses, vessel wall thickening and contrast uptake. Results: Ischemic changes of the brain tissue were seen in 24/27 patients and restricted diffusion suggestive of recent ischemia in 17/27; 25/27 patients had uni- or multifocal stenoses of intracranial arteries on TOF-MRA and $5 / 6$ had stenoses on DSA. Vessel wall thickening was identified in $25 / 27$, wall enhance-
\end{abstract}

ment in 23/27 patients. Conclusion: Wall thickening and intramural contrast uptake are frequent findings in patients with active cerebral vasculitis affecting large brain arteries. Further prospective studies are required to determine the specificity of this finding.

Copyright $\odot 2008$ S. Karger AG, Basel

\section{Introduction}

Ischemic brain symptoms are rare in young individuals and are usually not caused by atherosclerosis as in the elderly $[1,2]$. Apart from arterial dissections and cardiogenic emboli, progressive arterial stenoses due to inflammatory disease are an important cause of cerebral ischemia in this age group [3].

Inflammatory stenoses of arteries occur in autoimmunological diseases and due to vessel wall infection. Diagnostic problems arise if cerebral ischemia occurs before the underlying disease has been diagnosed [4] or if the findings are confined to intracranial arteries [5].

Cerebral angiography has long been the standard imaging procedure for patients with presumed intracranial stenoses. Cerebral or meningeal biopsy is regarded as the gold standard but rarely performed due to its risk and limited sensitivity.

The diagnosis of cerebral vasculitis is often based on fairly nonspecific inflammatory changes in the cerebro-

Dr. Wilhelm Küker

Department of Neuroradiology, West Wing

The John Radcliffe Hospital, Headley Way

Oxford OX3 9DU (UK)

Tel. +44 1865231 439, Fax +44 1865234 686, E-Mail Wilhelm.Kuker@ndm.ox.ac.uk 
spinal fluid (CSF) or serum. Hence, clinical criteria for the diagnosis have been proposed by Calabrese et al. [6] and Aviv et al. [7].

Because the medical treatment of cerebral vasculitis can have considerable side effects, a reliable noninvasive diagnostic test is needed.

On the background of its demonstrated diagnostic value in the temporal artery [8], the purpose of this study was to investigate the value of contrast-enhanced MRI for the diagnosis of intracranial vessel wall inflammation.

\section{Patients and Methods}

Patients with a clinical diagnosis of cerebral vasculitis affecting large brain arteries were retrieved retrospectively from the files of the Departments of Neurology and Neuropediatrics of the University of Tübingen, Germany, and from the Department of Clinical Neurology of the University of Oxford, UK. The diagnosis of cerebral vasculitis was based on histological or serological proof of vasculitis or clinically according to the criteria established by Calabrese [4] and Aviv et al. [7] for primary CNS vasculitis. These include new onset of acquired neurologic deficits with abnormalities of the brain vessels on imaging studies not explained by other causes. All patients had a clinical and imaging follow-up for at least 1 year or until their death.

Laboratory parameters investigated included inflammatory markers (red blood cell sedimentation rate, C-reactive protein, IgG, C3 complement), hematologic tests (platelets, hemoglobin, white blood cell count), lupus anticoagulant tissue thromboplastin inhibition index, platelet neutralization procedure and autoantibody profile (antinuclear antibody, antineutrophil cytoplasmic antibodies), anticardiolipin antibodies, and CSF abnormalities (CSF protein or CSF cell count, pressure, oligoclonal bands). Infections were investigated with viral and bacterial cultures, blood and CSF serology as well as CSF viral polymerase chain reaction.

Patients were further evaluated with EEG and cardiac ultrasound, partially with intravenous bubble contrast to assess a patent foramen ovale or transesophageal ultrasound to enhance resolution.

Brain biopsies were performed in 8 patients.

\section{Imaging}

All patients had MRI scans on 1.5-tesla systems (Siemens Magnetom Sonata, Siemens Medical Systems, Erlangen, Germany and General Electric Signa Edge, GE Medical Systems, Milwaukee, Wisc., USA) using circular polarized head coils.

Repetitive examinations (2-6) were performed in all patients. In total, $89 \mathrm{MRI}$ scans of patients with vasculitis were included in the study. Acquisition parameters varied slightly between the scanners used.

All patients had MRI scans which included $\mathrm{T}_{2}$-weighted turbo spin echo and $\mathrm{T}_{2}{ }^{*}$-weighted gradient echo sequences, fluid-attenuated inversion recovery images and a time-of-flight magnetic resonance angiography (TOF-MRA) of the circle of Willis. Moreover, all patients had intravenous contrast injections of $0.1 \mathrm{mmol} /$ $\mathrm{kg}$ body weight. High-resolution $\mathrm{T}_{1}$-weighted images with a slice thickness of $3 \mathrm{~mm}$ or less and the application of flow compensation were acquired using a spin echo sequence in 16 patients with vasculitis and in all controls. A fat saturation pulse was added in 9 vasculitis patients and in 21 controls. All patients and controls had examinations in at least two perpendicular planes of imaging.

Diffusion-weighted imaging (DWI) was performed in all patients and maps of the apparent diffusion coefficient were calculated and available at the time of evaluation.

Perfusion-weighted imaging was performed in 5 patients using a dynamic contrast bolus technique. The $\mathrm{T}_{2}{ }^{*}$-weighted echo planar imaging sequence had a temporal resolution of $1 \mathrm{~s}$ and contained 16 slices of $5 \mathrm{~mm}$ thickness. The basis of the evaluation were parameter maps of the time-to-peak measurements. The semiquantitative study was regarded as pathologic if an area of delayed signal change could be identified matching the clinical symptoms.

Intra-arterial digital subtraction angiography (DSA) was performed in 6 patients on a biplane angiographic system (Siemens Neurostar or Axiom Artis, Siemens Medical Solutions, Erlangen, Germany) with selective contrast injections into both internal carotid arteries and into at least one vertebral artery.

Image analysis was performed by two experienced neuroradiologists (T.N., W.K.) using a standardized review protocol based on review of the vasculitis literature [7]. All assessments were conducted by consensus in one sitting. Evaluation criteria were the presence, age and location of ischemic brain lesions, as well as the presence or absence of intracerebral hemorrhage.

The presence, location and degree of vascular stenoses on MRA and DSA were evaluated. Areas of abnormality in vascular imaging studies were then scrutinized on $\mathrm{T}_{1}$-weighted images before and after contrast injection and rated according to the presence of wall thickening, rendering a blinded review impossible. The degree of contrast uptake in altered vessel walls was rated as either absent, moderate or strong. Subsequently, other brain vessels were examined for signs of wall thickening and contrast uptake. Finally, the follow-up examinations were evaluated for signs of disease progression or remission.

\section{Results}

Twenty-seven patients seen between 1998 and 2006 met the inclusion criteria. Eight patients were children aged between 2 and 10 years ( 7 female, 1 male) and 19 were adults between 16 and 76 years of age (10 female, 9 male). The mean age of the patients was 27 years.

Clinical presentations were headache, seizures, focal neurologic deficits such as hemiparesis, hemifacial weakness, hemisensory and fine motor deficits. Further symptoms were diffuse neurologic deficits such as altered concentration, cognition, mood, or personality.

The most frequent clinical diagnosis in our patient group was primary angiitis of the CNS (PACNS) or childhood primary angiitis of the CNS (cPACNS). This diag- 
Table 1. Clinical and imaging findings in patients with cerebral vasculitis

\begin{tabular}{|c|c|c|c|c|c|c|c|c|c|c|c|c|c|}
\hline $\begin{array}{l}\text { Patien } \\
\text { No. }\end{array}$ & & Sex & Age & $\begin{array}{l}\text { Clin. } \\
\text { pres. }\end{array}$ & Location & Diagnosis & Remarks & $\mathrm{T}_{2}$ & DWI & MRA & $\begin{array}{l}\text { Wall } \\
\text { thick. }\end{array}$ & $\begin{array}{l}\text { Wall } \\
\text { enhan. }\end{array}$ & DSA \\
\hline 1 & S.G. & $\mathrm{F}$ & 2 & stroke & M1 R & cPACNS $^{1}$ & & abnormal & res. dif. & abnormal & 0 & 0 & n.a. \\
\hline 2 & M.S. & $\mathrm{F}$ & 3 & stroke & $\begin{array}{l}\text { carotid T L, ACA } \\
\text { bilaterally }\end{array}$ & $\mathrm{cPACNS}^{1}$ & $\begin{array}{l}\text { moyamoya } \\
\text { disease, } \\
\text { bypass surgery }\end{array}$ & abnormal & res. dif. & abnormal & + & + & n.a. \\
\hline 3 & P.B. & $\mathrm{F}$ & 3 & stroke & $\begin{array}{l}\text { PCA L, basilar artery, } \\
\text { carotid T R }\end{array}$ & $\mathrm{cPACNS}^{1}$ & & abnormal & res. dif. & abnormal & + & + & n.a. \\
\hline 4 & J.F. & $\mathrm{F}$ & 4 & stroke & carotid $\mathrm{T} \mathrm{R}$ and $\mathrm{P} 1 \mathrm{R}$ & cPACNS $^{1}$ & & abnormal & res. dif. & abnormal & + & + & n.a. \\
\hline 5 & T.S. & $\mathrm{M}$ & 4 & TIA & $\begin{array}{l}\text { basilar and vertebral } \\
\text { arteries bilaterally }\end{array}$ & $\begin{array}{l}\text { varicella-zoster } \\
\text { virus }\end{array}$ & & normal & no res. dif. & abnormal & + & + & n.a. \\
\hline 6 & M.K. & $\mathrm{F}$ & 5 & TIA & carotid T L & cPACNS $^{1}$ & & abnormal & no res. dif. & abnormal & + & + & n.a. \\
\hline 7 & R.K. & $\mathrm{F}$ & 9 & stroke & carotid $\mathrm{T} \mathrm{L}$ & cPACNS $^{1}$ & & abnormal & res. dif. & abnormal & + & + & n.a. \\
\hline 8 & B.K. & $\mathrm{F}$ & 10 & stroke & carotid T L & $\begin{array}{l}\text { varicella-zoster } \\
\text { virus }\end{array}$ & & abnormal & res. dif. & abnormal & + & + & n.a. \\
\hline 9 & H.C. & $\mathrm{F}$ & 16 & stroke & multiple small arteries & PACNS & biopsy proven & abnormal & no res. dif. & normal & + & + & normal \\
\hline 10 & J.G. & $\mathrm{F}$ & 18 & stroke & carotid T L & PACNS $^{1}$ & $\begin{array}{l}\text { parenchymal } \\
\text { enhancement }\end{array}$ & abnormal & res. dif. & abnormal & + & + & n.a. \\
\hline 11 & J.B. & $\mathrm{F}$ & 24 & bleed & multiple small arteries & Crohn's disease & bleeds & abnormal & no res. dif. & abnormal & + & + & $\begin{array}{l}\text { multiple } \\
\text { stenoses }\end{array}$ \\
\hline 12 & M.B. & $\mathrm{M}$ & 26 & TIA & carotid T L & $\begin{array}{l}\text { varicella-zoster } \\
\text { virus }\end{array}$ & $\begin{array}{l}\text { IgM antibodies } \\
\text { in CSF }\end{array}$ & normal & no res. dif. & abnormal & + & + & stenosis \\
\hline 13 & K.W. & $\mathrm{M}$ & 29 & TIA & M1 and C1 bilaterally & $\mathrm{PACNS}^{1}$ & & normal & no res. dif. & abnormal & + & 0 & n.a. \\
\hline 14 & K.G. & $\mathrm{F}$ & 29 & stroke & A1 bilaterally and M1 L & HIV and CMV & & abnormal & res. dif. & abnormal & + & + & n.a. \\
\hline 15 & C.T. & $\mathrm{M}$ & 33 & stroke & carotid T R & PACNS $^{1}$ & $\begin{array}{l}\text { deep white } \\
\text { matter stroke }\end{array}$ & abnormal & res. dif. & abnormal & + & + & n.a. \\
\hline 16 & A.M. & $\mathrm{F}$ & 37 & TIA & $\mathrm{ICA}+\mathrm{M} 1 \mathrm{R}$ & $\mathrm{PACNS}^{2}$ & biopsy proven & abnormal & no res. dif. & abnormal & + & + & stenosis \\
\hline 17 & R.F. & $\mathrm{M}$ & 37 & stroke & ICA bilateral & $\mathrm{PACNS}^{1}$ & $\begin{array}{l}\text { biopsy } \\
\text { inconclusive }\end{array}$ & abnormal & no res. dif. & abnormal & + & + & n.a. \\
\hline$\overline{18}$ & C.M. & $\mathrm{M}$ & 44 & stroke & carotid $\mathrm{T}$ bilaterally & HIV and HSV & massive infarct & abnormal & res. dif. & abnormal & + & + & n.a. \\
\hline 19 & C.P. & $\mathrm{M}$ & 45 & stroke & carotid $\mathrm{T}$ bilaterally & $\mathrm{PACNS}^{1}$ & infarct & abnormal & res. dif. & abnormal & + & + & $\begin{array}{l}\text { multiple } \\
\text { stenoses }\end{array}$ \\
\hline 20 & E.M. & $\mathrm{F}$ & 49 & stroke & M1 bilaterally & $\begin{array}{l}\text { LE, CMV } \\
\text { infection }\end{array}$ & $\begin{array}{l}\text { biopsy } \\
\text { inconclusive }\end{array}$ & abnormal & res. dif. & abnormal & + & + & n.a. \\
\hline 21 & K.L. & $\mathrm{M}$ & 50 & stroke & M1 L & APA & $\begin{array}{l}\text { biopsy } \\
\text { inconclusive }\end{array}$ & abnormal & no res. dif. & normal & + & 0 & n.a. \\
\hline 22 & B.D. & $\mathrm{F}$ & 51 & stroke & ICA bilaterally & HSV vasculitis & $\begin{array}{l}\text { biopsy } \\
\text { inconclusive }\end{array}$ & abnormal & no res. dif. & abnormal & + & + & n.a. \\
\hline 23 & S.T. & $\mathrm{F}$ & 53 & stroke & carotid $\mathrm{T}$ bilaterally & $\begin{array}{l}\text { systemic } \\
\text { sclerosis }\end{array}$ & infarct & abnormal & res. dif. & abnormal & + & + & $\begin{array}{l}\text { multiple } \\
\text { stenoses }\end{array}$ \\
\hline 24 & L.S. & $\mathrm{F}$ & 54 & stroke & $\begin{array}{l}\text { carotid } \mathrm{T} \text { and small } \\
\text { arteries bilaterally }\end{array}$ & PACNS & & abnormal & res. dif. & abnormal & 0 & 0 & \\
\hline 25 & B.U. & $\mathrm{M}$ & 62 & stroke & carotid $\mathrm{T}$ bilaterally & $\mathrm{PACNS}^{1}$ & & abnormal & res. dif. & abnormal & + & + & n.a. \\
\hline 26 & K.K. & $\mathrm{M}$ & 68 & TIA & carotid T R & $\begin{array}{l}\text { giant cell } \\
\text { vasculitis }\end{array}$ & biopsy proven & abnormal & res. dif. & abnormal & + & + & n.a. \\
\hline 27 & K.S. & $\mathrm{F}$ & 76 & stroke & $\begin{array}{l}\text { ICA T bilaterally, M1 L } \\
\text { basilar artery }\end{array}$ & $\mathrm{PACNS}^{2}$ & biopsy proven & abnormal & no res. dif. & abnormal & + & + & n.a. \\
\hline
\end{tabular}

$\mathrm{ACA}=$ Anterior cerebral artery; $\mathrm{PCA}=$ posterior cerebral artery; $\quad$ thick. $=$ wall thickening; Wall enhan. $=$ wall enhancement; $0=$ negative ICA = internal carotid artery; $\mathrm{M} 1=$ segment of the middle cerebral artery; $\mathrm{L}=$ left $\mathrm{R}=$ right; $\mathrm{HSV}=$ herpes simplex virus; $\mathrm{CMV}=$ cytomegalovirus; $\mathrm{APA}=$ antiphospholipid antibodies; LE = lupus erythematosus; Wall $+=$ positive; res. dif. $=$ restricted diffusion of protons.

${ }^{1}$ As defined by Calabrese et al. [6].

${ }^{2}$ Biopsy proven. 
nosis was confirmed by biopsy in 3 patients and rested on Calabrese criteria (new onset of an acquired focal or diffuse neurologic deficit and cerebral artery stenoses not explained otherwise) in 17 patients (cPACNS, $\mathrm{n}=8$; PACNS, $\mathrm{n}=9$ ).

Two patients had a combination of human immunodeficiency virus (HIV) infection and cytomegalovirus or herpes simplex virus infection. Other causes of vasculitis were antiphospholipid antibody syndrome, Crohn's disease, systemic sclerosis, herpes simplex virus and varicella-zoster virus infection (table 1).

\section{Parenchymal Changes}

At the time of the initial scan, 20 patients had suffered ischemic events lasting longer than $24 \mathrm{~h}$ (stroke), 6 patients ischemic deficits lasting less than $24 \mathrm{~h}$ [transient ischemic attacks (TIAs)] and 1 patient an intracerebral hemorrhage.

Areas of signal abnormality on $\mathrm{T}_{2}$-weighted images were seen in $24 / 27$ patients, restricted diffusion of protons in $17 / 27$ patients (fig. 1).

All patients with stroke had abnormal $\mathrm{T}_{2}$ and DWI studies at presentation. One of the patients suffering from a TIA showed restricted diffusion of protons in diffusionweighted MRI and 5 patients with TIAs had abnormal $\mathrm{T}_{2}$-weighted scans consistent with previous ischemic events in other territories.

The brain parenchymal findings were heterogeneous and comprised unilateral or bilateral chronic and acute infarcts and diffuse white matter changes. They included lesions in the hemispheres, brainstem and cerebellum, consistent with either hemodynamic deficiency or arterial occlusion. The hemodynamic lesions were mostly located in the deep white matter or border zones. Infarcts due to large artery occlusion matched the territories of the affected arteries. Strokes were seen in the territories of all major brain vessels and the lenticulostriate and choroidal arteries.

Two patients with normal $\mathrm{T}_{2}$ - and diffusion-weighted images had highly abnormal perfusion-weighted images. Parenchymal contrast enhancement in areas not affected by ischemia was encountered once. No specific pattern of injury could be identified for either the entire group of patients or for subgroups.

\section{Vascular Imaging}

Abnormal MRA findings (stenosis or wall abnormality) were encountered in $25 / 27$ patients (fig. 1,2 ). The stenoses were unilateral in 10/27 and bilateral in $15 / 27$ patients. They involved the large cerebral arteries (distal in- ternal carotid artery and carotid T, M1 and A1 segments, basilar artery and P1 segment) in 24 patients and the M2 segments three times.

Conventional cerebral angiography was performed in 6 patients. The angiographic diagnosis was based on disseminated intracranial stenoses not located at branching points.

Perfusion-weighted images were available in 5 patients. All scans showed an extensive area of delayed perfusion in the affected hemisphere. A perfusion abnormality was encountered in 2 patients with TIA and normal $\mathrm{T}_{2}$ and DWI. The findings on perfusion imaging were corroborated by consistent stenoses in MRA.

$\mathrm{T}_{2}{ }^{*}$-weighted images were acquired in 25 patients but did not show microbleeds or specific abnormalities of the affected vessel wall.

\section{Vessel Wall Abnormality}

All patients had multiplanar $\mathrm{T}_{1}$-weighted images of the brain before and after contrast administration, 19/27 on the first and $8 / 27$ on a subsequent scan.

Multiplanar high-resolution imaging with flow compensation was performed in 17/27 patients and an additional fat suppression technique was employed in 9/27 patients.

On slices of more than 3-mm thickness wall enhancement was occasionally mimicked by laminar flow adjacent to the vessel wall or by veins in the vicinity of the arteries. Vessel wall enhancement was rated as unequivocal, if it could be demonstrated in more than one plane. Findings often consisted of massive enhancement. Vessel wall thickening and contrast enhancement coincided in locations with MRA or DSA abnormality.

Vessel wall thickening was identified in $25 / 27$, wall enhancement in 23/27 patients according to these criteria.

\section{Discussion}

Nearly all patients with cerebral vasculitis presented here showed signs of acute or chronic brain ischemia or reduced brain perfusion. However, no specific pattern could be identified as findings were variable and depended on the extent of the disease, the location and severity of the stenoses as well as of the quality of collateral blood supply. In accordance with literature reports, involvement of the basal ganglia was frequent in children and in all patients with M1 abnormalities [7]. Otherwise different types of hemodynamic and territorial infarcts were encountered depending on the vessels involved. Perfu- 

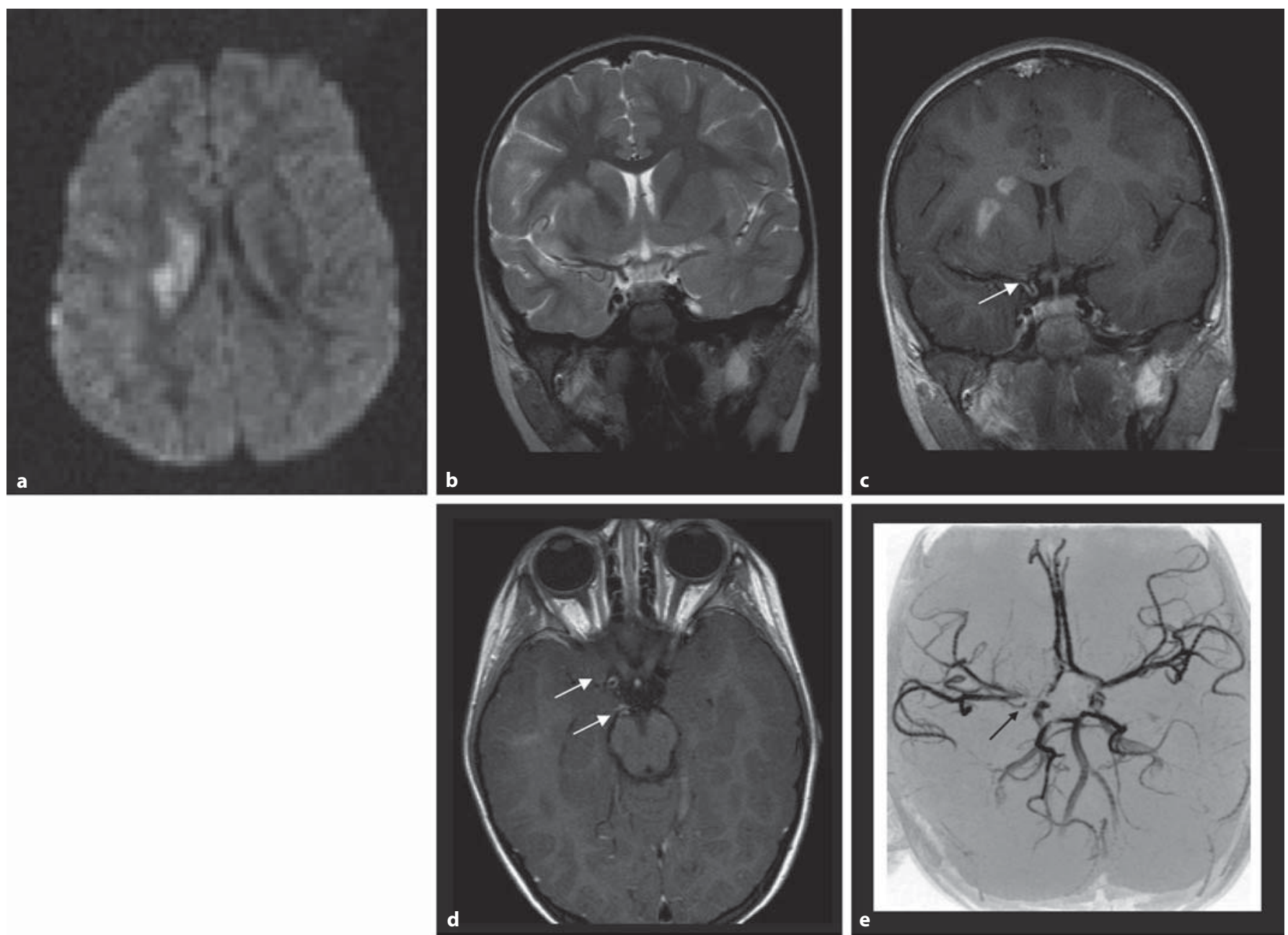

Fig. 1. cPACNS; mild right hemispheric stroke with hemiparesis 10 days earlier; 4-year-old girl. a DWI. There is restricted diffusion of protons in the right basal ganglia. $\mathbf{b}$ The $\mathrm{T}_{2}$-weighted MRI shows only minor hyperintense signal change in the basal ganglia on the right sparing the internal capsule. $\mathbf{c}$ The contrast-enhanced coronal $\mathrm{T}_{1}$-weighted image (slice thickness $3 \mathrm{~mm}$, flow compensation) after contrast injection $(0.1 \mathrm{mmol} / \mathrm{kg}$ Gd-DTPA) through the distal internal carotid artery shows contrast enhancement in the right caudate and lentiforme nuclei. There is clearly enhancement in the wall of the right distal internal carotid artery (arrow). d The axial $\mathrm{T}_{1}$-weighted image shows wall enhancement in the right distal internal carotid artery and the right P1 segment (arrow). e The TOF-MRA shows an abnormality of the right internal carotid artery around the carotid $\mathrm{T}$, but also some narrowing in the right P1 (arrow). sion imaging was helpful to identify areas of reduced brain perfusion without structural damage in the early stages of the disease.

TOF-MRA is well suited to identify stenoses in patients with intracranial vasculitis $[9,10]$. Using this technique, 25/27 patients were found to have abnormalities affecting cerebral vessels proximal to the A2, M2 and P2 segments.

A cerebral angiogram was performed in some patients with low flow symptoms to assess a possible intracranial angioplasty, a now established treatment option in intracranial stenoses $[11,12]$. However, in our patients the findings were regarded as unsuitable for endovascular treatment.

Thickening of artery walls in areas of flow abnormality was demonstrated in $25 / 27$ patients in our group. Further signs of abnormality were luminal narrowing, asymmetric vessel diameter and eccentric vascular lumen.

MRI showed mural enhancement in the enlarged vessel wall in 23/27 our patients, however not to the same 

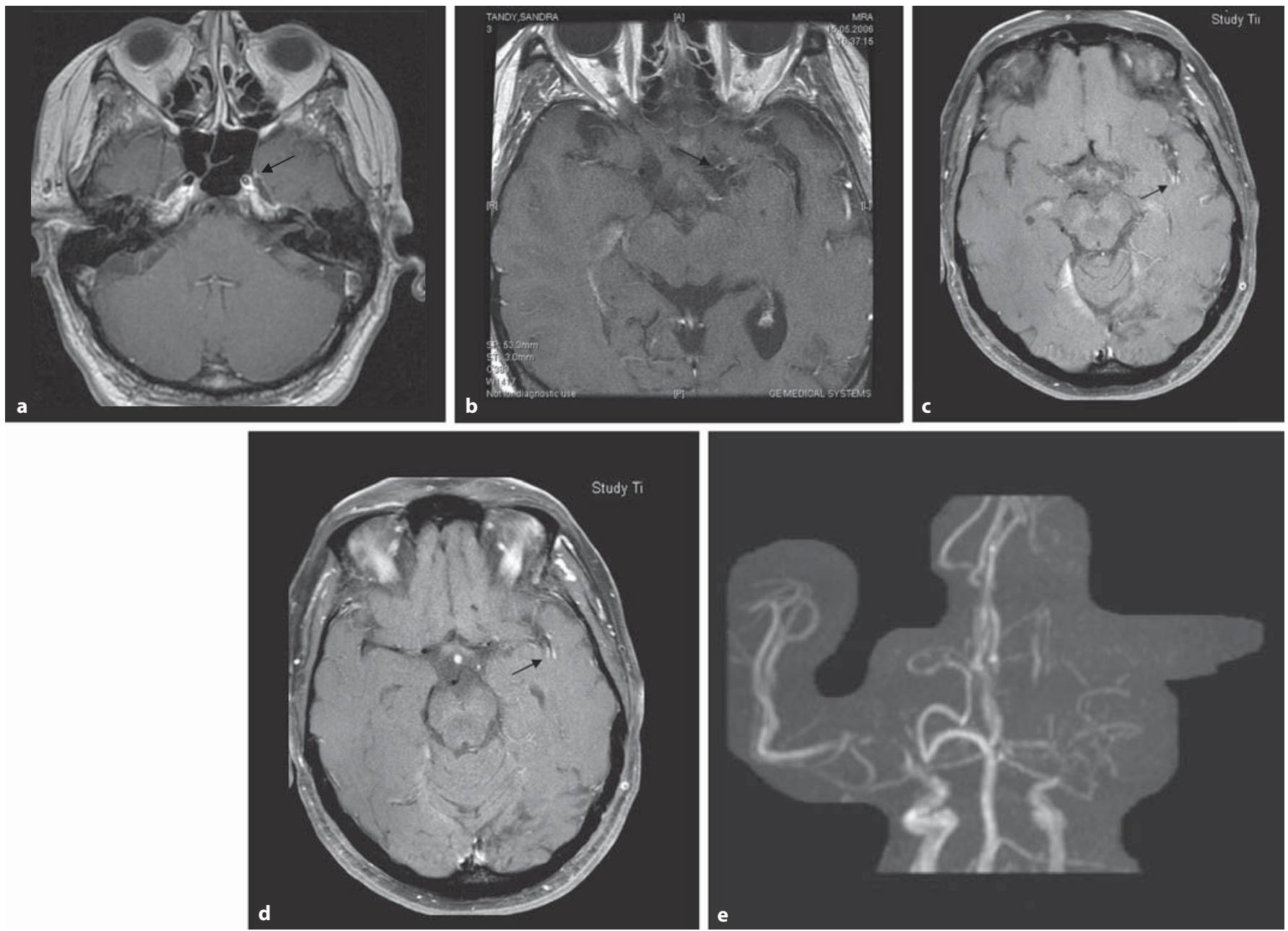

Fig. 2. Fifty-three-year-old woman with right-sided hemiparesis and aphasia. a-d High-resolution $\mathrm{T}_{1}$-weighted images after contrast injection $(0.1 \mathrm{mmol} / \mathrm{kg})$ with fat suppression and flow compensation. a This $\mathrm{T}_{1}$-weighted contrast-enhanced image at the level of the skull base shows an enlargement of the left distal internal carotid artery (arrow) compared to the right. b At a slightly higher location, there is contrast enhancement in the M1 seg- ment on the left (arrow). c Wall enhancement is also seen in middle cerebral artery branches in the left sylvian fissure (arrow). d This image slightly more apical confirms the intramural enhancement pattern (arrow). e The TOF-MRA shows severe flow abnormality in the left distal internal carotid artery and A1 as well as M1 segments. There are also severe stenoses on the right. extent in all scans. Mural contrast uptake was confined to some areas of the vasculature and other segments were clearly normal. Wall enhancement is an established imaging sign of vessel wall inflammation extracranially. It has been documented as an important imaging sign of giant cell (temporal) arteritis $[8,13]$.

Cerebral vasculitis is a late complication of HIV [14]. Vessel wall enhancement caused by viral infection has been reported in 2 patients with HIV-associated vasculitis [15]. We present similar findings in 2 further patients with HIV and viral vasculitis (patients No. 18 and 21). Vessel wall contrast enhancement has also been reported in radiation vasculopathy [16].

Varicella-zoster virus is a frequent cause of vasculitis affecting the carotid $\mathrm{T}$ and adjacent cerebral vessels, but also the basilar artery [17]. Although many patients had CSF findings consistent with previous varicella infection, the lack of IgM antibodies or viral DNA did not permit an unequivocal diagnosis. However, at least in the children and young adults presented here, varicella vasculitis 
remains a likely cause as the pattern of vascular involvement is rather uniform and does match the typical findings of varicella-zoster virus vasculitis.

In adult patients, the pathogenesis of vasculitis was even more difficult to establish. A brain biopsy was performed in 8 patients but did only yield a positive result in 3 cases. An isolated CNS vasculitis was diagnosed twice and a giant cell vasculitis once.

Cytomegalovirus vasculitis was found in 1 adult patient suffering from AIDS and 1 patient with lupus erythematosus. In the AIDS patients, the vessel wall inflammation and contrast uptake were massive and easily dem- onstrated. Other patients had CSF findings consistent with a herpes simplex virus infection as a possible cause of vessel wall stenoses, 1 on a background of AIDS.

In conclusion, MRI and MRA are valuable tools for the diagnosis of cerebral vasculitis. Multiplanar, high-resolution contrast-enhanced $\mathrm{T}_{1}$-weighted images through the affected arteries demonstrate vessel wall thickening and enhancement in the majority of patients. A prospective trial will be necessary to establish the sensitivity and specificity of vessel wall enhancement for cerebral vasculitis.

\section{References}

1 Carvalho KS, Garg BP: Arterial strokes in children. Neurol Clin 2002;20:1079-1100, vii.

-2 Cerrato P, Grasso M, Imperiale D, Priano L, Baima C, Giraudo M, Rizzuto A, Azzaro C, Lentini A, Bergamasco B: Stroke in young patients: etiopathogenesis and risk factors in different age classes. Cerebrovasc Dis 2004; 18:154-159.

- 3 Benseler SM, Silverman E, Aviv RI, Schneider R, Armstrong D, Tyrrell PN, de Veber G: Primary central nervous system vasculitis in children. Arthritis Rheum 2006;54:1291-1297.

4 Calabrese LH: Diagnostic strategies in vasculitis affecting the central nervous system. Cleve Clin J Med 2002;69(suppl 2):SII105SII108.

5 Volcy M, Toro ME, Uribe CS, Toro G: Primary angiitis of the central nervous system: report of five biopsy-confirmed cases from Colombia. J Neurol Sci 2004;227:85-89.

6 Calabrese LH, Furlan AJ, Gragg LA, Ropos TJ: Primary angiitis of the central nervous system: diagnostic criteria and clinical approach. Cleve Clin J Med 1992;59:293-306.
7 Aviv RI, Benseler SM, Silverman ED, Tyrrell PN, Deveber G, Tsang LM, Armstrong D: MR imaging and angiography of primary CNS vasculitis of childhood. AJNR Am J Neuroradiol 2006;27:192-199.

8 Bley TA, Wieben O, Vaith P, Schmidt D, Ghanem NA, Langer M: Magnetic resonance imaging depicts mural inflammation of the temporal artery in giant cell arteritis. Arthritis Rheum 2004;51:1062-1063; author reply 1064.

9 Pomper MG, Miller TJ, Stone JH, Tidmore WC, Hellmann DB: CNS vasculitis in autoimmune disease: MR imaging findings and correlation with angiography. AJNR Am J Neuroradiol 1999;20:75-85.

10 Demaerel P, De Ruyter N, Maes F, Velghe B, Wilms G: Magnetic resonance angiography in suspected cerebral vasculitis. Eur Radiol 2004;14:1005-1012.

-11 SSYLVIA Study Investigators: Stenting of Symptomatic Atherosclerotic Lesions in the Vertebral or Intracranial Arteries (SSYLVIA): study results. Stroke 2004;35:13881392.

12 Marks MP, Wojak JC, Al-Ali F, Jayaraman M, Marcellus ML, Connors JJ, Do HM: Angioplasty for symptomatic intracranial stenosis: clinical outcome. Stroke 2006;37: 1016-1020.
13 Bley TA, Wieben O, Uhl M, Thiel J, Schmidt D, Langer M: High-resolution MRI in giant cell arteritis: imaging of the wall of the superficial temporal artery. AJR Am J Roentgenol 2005; 184:283-287.

14 Evers S, Nabavi D, Rahmann A, Heese C, Reichelt D, Husstedt IW: Ischaemic cerebrovascular events in HIV infection: a cohort study. Cerebrovasc Dis 2003;15:199-205.

15 Berkefeld J, Enzensberger W, Lanfermann $\mathrm{H}$ : MRI in human immunodeficiency virusassociated cerebral vasculitis. Neuroradiology 2000;42:526-528.

16 Aoki S, Hayashi N, Abe O, Shirouzu I, Ishigame K, Okubo T, Nakagawa K, Ohtomo K, Araki T: Radiation-induced arteritis: thickened wall with prominent enhancement on cranial MR images report of five cases and comparison with 18 cases of Moyamoya disease. Radiology 2002;223:683-688.

17 Gilden DH, Mahalingam R, Cohrs RJ, Kleinschmidt-DeMasters BK, Forghani B: The protean manifestations of varicella-zoster virus vasculopathy. J Neurovirol 2002;8 (suppl 2):75-79. 